\title{
Shunt malfunction and perioperative complications with non-programmable shunt valves in patients with normal pressure hydrocephalus in a series of 195 consecutive patients Evan Marlin*1, James Golomb ${ }^{2}$ and Jeffery Wisoff ${ }^{3}$
} \author{
York, NY 10016, USA \\ Email: Evan Marlin* - evan.marlin@gmail.com \\ * Corresponding author \\ from 52nd Annual Meeting of the Society for Research into Hydrocephalus and Spina Bifida \\ Providence, RI, USA. II-14 June 2008 \\ Published: 3 February 2009 \\ Cerebrospinal Fluid Research 2009, 6(SuppI I):S44 doi:I0.II86/I743-8454-6-SI-S44
}

Address: ${ }^{1}$ NYU School of Medicine, Rubin Hall, 435 East 30th St, \#721, New York, NY 10016, USA, 2School of Medicine Neurology and Aging, 550 First Avenue, Milhauser Labs 3 N-312A, New York, NY 10016, USA and ${ }^{3}$ School of Medicine Neurosurgery, 317 East 34th Street, \#1002, New

This abstract is available from: http://www.cerebrospinalfluidresearch.com/content/6/SI/S44

(C) 2009 Marlin et al; licensee BioMed Central Ltd.

\section{Background}

Normal pressure hydrocephalus has increasingly been recognized as a cause of reversible gait disorder, dementia, and incontinence; however, unlike paediatric hydrocephalus the longevity of shunt survival and complications are poorly documented.

\section{Materials and methods}

Retrospective chart review was conducted on normal pressure hydrocephalus patients who received prospective evaluation at an adult hydrocephalus center and underwent ventriculoperitoneal or ventriculoatrial shunting with either Delta $1(n=140)$ or Orbis Sigma $(n=55)$ valves between September 1999 and June 2007. All patients received treatment and follow-up from a single surgeon. Time until first revision, time until first subdural hematoma requiring intervention, death - confirmed by the social security death index - and clinical outcome were assessed.

\section{Results}

As a group of 195 patients, the mean and median age at time of surgery was 77.5 years, with a standard deviation of 7.0 years. At the end of the first year $8 \%$ of patients had expired, and at the end of five years post-shunt 47 patients or $27 \%$ of the patient population had expired. Age was an independent predictor of death associated with an Odds
Ratio of $1.05(\mathrm{p}=0.046)$. At one year post-shunt, $16 \%$ patients required distal revision and at five years $24 \%$ of patients required distal revision; $58 \%$ of distal malfunctions occurred in the first post-operative year. Nineteen subdurals were associated with this group and occurred early post-operatively - 17 subdurals $(90 \%)$ occurred within the first 90 days. The incidence of subdurals in the OSV group was associated with an Odd Ratio of $2.95(\mathrm{p}=$ 0.026 ) as compared to the D1 group. Additionally, age was also an independent predictor of SDH with an Odd Ratio of $1.11(\mathrm{p}=0.009)$. Initial clinical improvement maybe associated increased patient survival. Unfortunately due to the relatively small population size and statistical power considerations these results are still tentative $(\mathrm{p}=0.15)$. Six shunt infections occurred, yielding a $3 \%$ rate of infection.

Individual analysis of the Delta 1 and Orbis Sigma valves with Kaplan-Meier estimates show no statistical significant differences in 5-year patient survival, incidence of distal occlusions, or clinical outcome; however with regard to the occurrence of subdurals, increased age and the Orbis Sigma were associated with a significant increase in occurrence. 


\section{Conclusion}

Evaluation of these 195 patients has given a clearer picture as to the longevity of shunts in normal pressure hydrocephalus. Further evaluation is still necessary to determine how other clinical factors may have possible effects on shunt survival and outcomes in these patients.

Publish with Bio Med Central and every scientist can read your work free of charge

"BioMed Central will be the most significant development for disseminating the results of biomedical research in our lifetime. " Sir Paul Nurse, Cancer Research UK

Your research papers will be:

- available free of charge to the entire biomedical community

- peer reviewed and published immediately upon acceptance

- cited in PubMed and archived on PubMed Central

- yours - you keep the copyright 